\title{
El cine como espejo diferido: el concepto de transferencia en André Bazin y Stanley Cavell
}

\section{Lourdes Esqueda Verano 1}

Recibido: 01/03/2018

Aprobado por pares: 07/09/2018
Enviado a pares: 01/03/2018

Aceptado: 11/10/2018

DOI: 10.5294/pacla.2019.22.3.4

Para citar este artículo / to reference this article / para citar este artigo Esqueda-Verano, L. (2019). El cine como espejo diferido: el concepto de transferencia en André Bazin y Stanley Cavell. Palabra Clave, 22(3), e2234. DOl: http://doi.org/ 10.5294/ pacla.2019.22.3.4

\section{Resumen}

Este artículo rescata la visión de André Bazin para señalar su actualidad en el momento de tratar la siempre cambiante naturaleza del cine, específicamente ante las nuevas formas cinematográficas. La teoría de Bazin se sustenta de un modo aparentemente paradójico sobre la identidad entre el modelo real y su imagen fotográfica, una premisa compleja que será desarrollada décadas más tarde por el filósofo estadounidense Stanley Cavell. En este trabajo, se indicará, primero, el sentido de esta identidad. En vistas a demarcar el alcance y las repercusiones de esta identidad ontológica en la percepción de la imagen cinematográfica, se abordará el concepto en relación con el de semejanza y con el de causalidad, para conocer la especificidad de este. A continuación, se explicará su alcance a partir del concepto de transferencia. Para llegar a una comprensión cabal de este proceso, se analizará el modo en el que aparece en los trabajos de ambos teóricos. Una de las principales conclusiones del artículo es que el realismo no es algo de lo

1 orcid.org/0000-0002-2120-944X. Universidad de Navarra, España. lesqueda@unav.es 
que el sujeto deba investir a la imagen fotográfica, sino que es una propiedad de esta, en virtud de la transferencia de realidad del objeto a la imagen. Con ello, se muestra cómo el espectador de cine, frente a la pantalla, lleva a cabo un acto análogo al de la percepción cotidiana: el reconocimiento de una realidad representada en pantalla.

\section{Palabras clave (Fuente: tesauro de la Unesco)}

Cine; realismo; teoría; fotografía; transferencia; André Bazin; Stanley Cavell. 


\section{Cinema as a Delayed Mirror: The Concept of Transfer in André Bazin and Stanley Cavell}

\section{Abstract}

This article revives André Bazin's vision to suggest its relevance at the time of dealing with the ever-changing nature of cinema, specifically with new cinematographic forms. Bazin's theory is based —in an apparently paradoxical way - on the identity between the actual model and its photographic image, a complex premise that would be elaborated decades later by the American philosopher Stanley Cavell. This paper states first the meaning of this identity. In order to delimit the scope and repercussions of this ontological identity in the perception of a cinematographic image, the concept is approached in relation to those of similarity and causality. Then, its scope is explained from the concept of transfer. To arrive at a thorough understanding of this process, the way in which it is expressed in both theorists' works is analyzed. One of the main conclusions is that realism is not something to be conferred by the subject on the photographic image, but its property by virtue of the transfer of reality from the object to the image. This shows how the film viewer, in front of the screen, carries out a process analogous to that of everyday perception: recognizing a reality depicted on the screen.

\section{Keywords (Source: Unesco Thesaurus)}

Cinema; realism; theory; photography; transfer; André Bazin; Stanley Cavell. 


\section{0 cinema como espelho diferido: o conceito de transferência em André Bazin e Stanley Cavell}

\section{Resumo}

Este artigo resgata a visão de André Bazin para mostrar sua atualidade no momento de tratar da sempre oscilante natureza do cinema, em específico diante das novas formas cinematográficas. A teoria de Bazin é sustentada de um modo aparentemente paradoxal sobre a identidade entre o modelo real e sua imagem fotográfica, um princípio complexo que será desenvolvido décadas mais tarde pelo filósofo estadunidentese Stanley Cavell. Neste trabalho, será indicado o sentido dessa identidade. A fim de delimitar o alcance e as repercussões dessa identidade ontológica na percepção da imagem cinematográfica, será abordado o conceito em relação com o de semelhança e de causalidade, para conhecer sua especificidade. Em seguida, será explicado seu alcance a partir do conceito de transferência. Para chegar a uma compreensão coerente do processo, será analisado o modo em que aparece nos trabalhos de ambos os teóricos. Uma das principais conclusões deste artigo é que o realismo não é algo de que o sujeito deva investir à imagem fotográfica, mas sim uma propriedade desta, em virtude da transferência de realidade do objeto à imagem. Com isso, mostra-se como o espectador de cinema, diante da "telona", realiza um ato análogo ao da percepção cotidiana: o reconhecimento de uma realidade representada na tela.

\section{Palavras-chave (Fonte: tesauro da Unesco)}

Cinema; realismo; teoria; fotografia; transferência; André Bazin; Stanley Cavell. 


\section{Introducción}

El pensamiento de André Bazin, desplegado en las décadas de los cuarenta y cincuenta, continúa modulando en la actualidad una fecunda conversación en el mundo académico y crítico sobre el papel del cine y lo audiovisual en la representación de la realidad, debate que se ha avivado con la llegada de la tecnología digital. ${ }^{2}$ Uno de los asuntos más controvertidos de la teoría bazaniana es la identidad ontológica de la imagen fotográfica y cinematográfica respecto del modelo. Bazin defiende que la imagen fotográfica es la cosa misma, pero liberada de sus contingencias temporales (1966, p. 18), una expresión frecuentemente recibida como una hipérbole o, en el mejor de los casos, como una paradoja. Sin embargo, los escritos de Bazin se alejan de esas interpretaciones y buscan más bien definir la materia prima del cine como un nuevo tipo de imagen que se encuentra en un lugar intermedio entre la realidad y la representación. Esta tesis fue retomada años más tarde, en la década de los setenta, por el filósofo estadounidense Stanley Cavell, considerado por muchos como el último gran autor de la teoría clásica del cine (Morgan, 2015, p. 163; Rothman, 2007, pp. 54-61). Cavell, que reconoce a Bazin como inspiración en su conocido libro The world viewed: Reflections on the ontology of film (1979, p. xxiii), desarrollará su propia explicación sobre la identidad ontológica entre la imagen cinematográfica y el mundo físico. En el presente artículo, se analizarán y pondrán en diálogo los principales argumentos esgrimidos por Bazin y Cavell sobre esta cuestión.

El artículo está dividido en cinco epígrafes. En los dos primeros, se ofrece una clarificación conceptual sobre la mencionada identidad ontológica. Se distingue entre semejanza e identidad al abordar la relación entre el modelo y su imagen fotográfica; y luego se matiza el papel que desempeña la causalidad en la producción de la imagen. El tercer epígrafe está dedicado al estudio del concepto clave al que alude Bazin en "Ontologie de

2 Como parte de esta revitalización, destacaría los números monográficos sobre Bazin, como "Focus on Bazin” (Totaro \& Younger, 2003); “Feature Bazin” (VV. AA., 2007); "Belief in cinema” (During \& Trahair, 2012); "Introduction: Revisiting André Bazin” (Smith, 2013). Además de algunos estudios recientes reseñables sobre la figura del autor (Andrew, 2010; Bazin, 2014; Bertoncini, 2009; Andrew \& Joubert-Laurencin, 2011; Ungaro, 2000). O la reedición de la conocida biografía de Bazin reeditada por el propio Andrew (2013). 
l'image photographique", que es el de transferencia. Resulta necesario precisar aquí que este término no aparece en la traducción castellana de $i Q u e ́ e s$ el cine?, pues su traductor optó por interpretar transfert como "transfusión" (1966, p. 18), modificando sustancialmente el sentido de la frase original: "La fotografía se beneficia de la transferencia de la realidad de la cosa a su reproducción" (1958, p. 16). ${ }^{3}$ Aunque transfusión y transferencia pueden ser términos afines, es importante, como se explicará más adelante, mantener el original "transferencia", ya que la identidad ontológica entre modelo e imagen fotográfica depende de este. El penúltimo epígrafe está dedicado a caracterizar el proceso de transferencia que propicia la identidad ontológica entre modelo e imagen fotográfica y cinematográfica. En este punto, las reflexiones de Cavell son fundamentales para lograr una comprensión cabal de este proceso. Finalmente, en el quinto apartado, se da cuenta del acto de reconocimiento, identificado por Bazin y Cavell como el efecto distintivo de la imagen de registro en el espectador.

\section{Distinción entre semejanza e identidad}

La identidad ontológica a la que alude Bazin no puede comprenderse desde el punto de vista de la semejanza, porque, si bien es cierto que el origen causal de la fotografía implica habitualmente una relación de parecido, la semejanza no agota las particularidades del proceso fotográfico ni necesariamente aparece en este. Basta con pensar en las imágenes fotorrealistas generadas por ordenador o en la fotografía abstracta para descartar ambas suposiciones. La separación entre el mero parecido y el poder de la imagen fotográfica y cinematográfica aparece de una manera evidente cuando el teórico distingue entre el verdadero realismo - en el que confluye lo concreto y lo abstracto de la expresión cinematográfica - y el pseudorrealismo —que se satisface con la ilusión de las formas- (1958, p. 13). Bazin describe el pseudorrealismo como un realismo de las apariencias, meramente formal, en el que el parecido juega las veces de ilusión óptica, "du trompel'oeil, ou du trompe-l'esprit" (p. 13). Contrario a lo que algunos teóricos como Philippe Dubois o Nöel Carroll han defendido, ${ }^{4}$ que la fotografía sea

3 Traducción del autor.

4 Dubois enmarca a Bazin como bisagra entre dos posturas complementarias de la fotografía: el discurso de la mímesis, según la cual la fotografía es esencialmente realista debido al parecido entre el modelo y la imagen resultante, 
una copia más fiel del mundo exterior no es, para Bazin, su rasgo más definitivo. Lo esencial de la fotografía, según Bazin, radica en que esta actúa como una presencia incorpórea de la propia realidad, llegando a afectarnos al igual que la realidad misma, como un copo de nieve o una flor (p. 15). Por eso, Bazin niega que el realismo del cine sea el resultado de la copia perfecta de las apariencias; y subraya más bien que "las virtualidades estéticas de la fotografía residen en su capacidad de revelación de lo real” (p. 18). En esta línea, Jean Ungaro comenta que, para Bazin, el cine es un arte radicalmente distinto del resto, porque "nos concede ver en directo la esencia de las cosas” (2000, p. 145). Desde la perspectiva fenomenológica en la que se sitúa Bazin, lo esencial a un fenómeno es aquello que lo constituye necesariamente. Lo que distingue a un objeto de otros. Al hablar de la esencia de las cosas, hablamos de su identidad, de su configuración como un esto concreto. Bajo esta luz, Bazin advierte que la fotografía del siglo XIX fue, por mucho tiempo, inferior a la pintura desde el punto de vista de semejanza, ya que la pintura realista contaba con color y con mayor definición que las fotografías de principios de siglo. Y, sin embargo, una pintura jamás podría despertar en el espectador la misma sensación que una fotografía, porque en la fotografía "la imagen puede estar borrosa, deformada, decolorada, carecer de valor documental, pero procede por su génesis de la ontología del modelo: es el modelo" (1958, p. 16). Cuando Bazin menciona la procedencia de la imagen fotográfica como su rasgo fundamental, alude a su origen causal y, sin embargo, como se verá, tampoco agota su sentido en este origen.

\section{Distinción entre causalidad e identidad}

Desde que Peter Wollen publicó a finales de la década de los sesenta su obra Signs and meaning in the cinema, la teoría baziniana se ha identificado con el concepto de indexicalidad, pese a que Bazin nunca usó este término en sus casi 2600 textos publicados. Recientemente, en la academia se ha despertado un renovado interés por comprender a qué apuntaba Bazin en su "Ontologie" fuera del paradigma semiótico en que se había encasillado este tipo

y el discurso de la huella, en el que la imagen remite, como índice, hacia un referente real (1986, pp. 27-31, 42-7). Friday (2005) identifica esta misma confusión en la lectura que Carroll hace de la teoría baziniana, dado que toma la identidad a la que alude Bazin como una "identidad perceptual” (pp. 345-346). 
de estudios. En esta línea, Daniel Morgan advierte que Bazin recurre más a los términos identidad o equivalencia para hablar de la relación entre la realidad y su imagen fotográfica que al término huella (2006, p. 448). La imagen fotográfica es una huella de lo real, en el sentido de que se origina gracias al contacto automático de los patrones de luz con el soporte, es decir, sin intervención creativa por parte del sujeto en la formación de la imagen (cfr. Brubaker, 1993, p. 60). Sin embargo, Bazin apunta hacia algo que supera las fronteras de la causalidad: la huella de lo real es, en cierto sentido, lo real.

Cuando Bazin alude a esta equivalencia, no se refiere a una metáfora perceptiva al estilo de Kendall L. Walton, quien reinterpreta la identidad ontológica desde el punto de vista de la "transparencia". 5 De acuerdo con Walton, la imagen de registro es transparente respecto de lo real y, así, propicia una clase particular de percepción en la que el sujeto actúa como si lo representado fuese ontológicamente igual a lo real (2008, p. 83). Esta relación se puede representar esquemáticamente como se muestra en la figura 1.

\section{Figura 1. Relación en el acto de percepción}

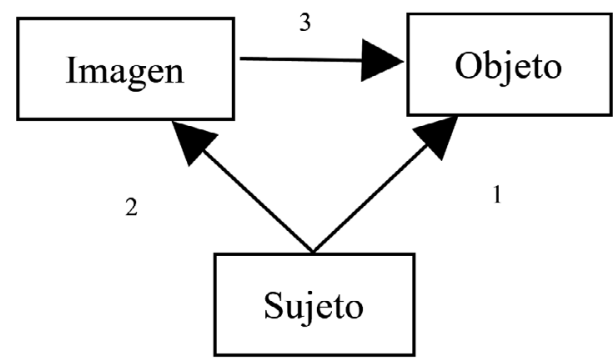

Fuente: elaboración propia.

La relación 1 es la percepción cotidiana que un sujeto tiene de una realidad. La relación 2 es la percepción que un sujeto tiene de una imagen fotográfica. La imagen remite al objeto real (relación 3) de acuerdo con su semejanza. Ahora bien, según la relación semiótica propia de un signo, el

5 Walton (2008) sigue principalmente a Cavell cuando desarrolla este concepto, aunque también muestra un conocimiento de la teoría de André Bazin y Erwin Panofsky, como puede comprobarse en esta referencia: "La verdad en lo que [Bazin, Panofsky] dicen, y en lo que [Cavell] sugiere, es que 'u7na fotografía es del mundo' ('del mundo o de la naturaleza'), mientras que 'una pintura es un mundo'” (p. 83, n. 4). 
sujeto en la relación 2 no conoce la realidad, sino un signo suyo o, en todo caso, la realidad a través del signo. Sin embargo, según explica Walton, la imagen fotográfica tiene una relación tal con lo real que se percibe como si fuera lo real, de modo que el sujeto conoce efectivamente la realidad cuando la mira. Esta es la llamada tesis de la transparencia. Este peculiar efecto de la fotografía lleva a Walton a comprender la cámara fotográfica como un espejo con memoria, que refleja un acontecimiento pasado. Aparentemente, esta conclusión de Walton no dista de la de Bazin, quien explica que "la pantalla, por su relación con el hecho representado, no es más que una suerte de espejo con reflejo diferido" (1953, p. 12).

Pese a las coincidencias entre Walton y Bazin, ambos difieren en un punto fundamental: Bazin no considera que la imagen sea como si fuera lo real, sino que la imagen es una huella visual de lo real y, paradójicamente, en cierto sentido es lo real, un momento de lo real, separado del tiempo, momificado, disponible para repetir una percepción de forma indefinida. Esta paradoja presente en la "Ontologie" baziniana será debidamente explicada mediante el concepto de transferencia.

\section{El concepto de transferencia}

El primer paso para definir la transferencia baziniana consiste en aclarar que, cuando Bazin habla de la imagen fotográfica como huella de lo real, no está propiamente interesado en la idea de un objeto físico que reduplica el mundo, sino más bien en la imagen como una particular forma apartada del tiempo histórico y que, sin embargo, permite una nueva observación del mundo en un presente y es capaz de reproducirse o re-presentarse ad infinitum. La ontología baziniana no se centra en el objeto fotografía (soporte + imagen), sino en la imagen fotográfica en sí. De ahí que Bazin deje de lado su evidente condición de materia distinta de la realidad y se esmere por observar las particularidades de la imagen misma. Como se verá en el cuarto epígrafe, cuando se dé cuenta de la identidad ontológica, Bazin y, más adelante, Cavell coinciden en señalar que el reconocimiento (reconnaissance, acknowledgement) es la característica central de la imagen de registro (fotográfica y cinematográfica), ya que en ningún otro arte se da el proceso de transferencia de la realidad del objeto a la imagen. 
Pese a la centralidad que la transferencia desempeña en la teoría baziniana, pocas veces se le ha prestado atención a este concepto. Como explica Morgan, esta indiferencia "no se debe a que la idea de identidad ontológica haya sido rechazada, sino más bien a que ha sido ignorada" (2006, p. 450). Morgan advierte acertadamente que, salvo Carroll (1988, p. 125), Andrew (1993) y, precisamente, Cavell (1979, pp. 16-23), ningún otro filósofo o académico se había planteado como una posibilidad real que Bazin hablase en serio y no en sentido figurado sobre la identidad ontológica entre fotografía y modelo. ${ }^{6}$ Recientemente, sin embargo, han surgido nuevos estudios que indagan el verdadero sentido en que Bazin expresó esta afirmación (cfr. Morgan, 2006; Esqueda-Verano, 2018).

Primero, es necesario comprender en qué consiste tal proceso. Una transferencia consiste en pasar o llevar algo desde un lugar a otro. Transferir algo implica a) que el objeto transferido no puede estar simultáneamente en los dos sitios y b) que lo transferido es igual a sí mismo en el punto de partida y el destino. En la imagen fotográfica, se produce una captura del objeto real que queda guardada en un soporte distinto del cuerpo material que lo origina. Pero dicho objeto no se transfiere en su totalidad, sino que se ve desprendido de su corporalidad. Al tomar una fotografía de algo $x$, por ejemplo, del rostro de Humphrey Bogart, lo que se transfiere no es toda su realidad física, sino parte de ella: la realidad visualmente perceptible y temporal-concreta del instante en que fue fotografiada o filmada.

La realidad visual o apariencia de un objeto es contingente, pues esta cambia, evoluciona o se deteriora con el paso del tiempo. El objeto real que es capturado en un momento, al pasar este momento, ya no es el mismo. Sin embargo, en la fotografía nos encontramos necesariamente con esa apariencia concreta e inmutable. Ocurre lo mismo respecto de la temporalidad, porque la realidad temporal-concreta de un objeto remite a un momento muy preciso que en el proceso fotográfico también sufre un cambio esencial: es sustraído del cauce temporal. De modo que no solo nos encontramos ante

6 La aportación de Carroll, sin embargo, resulta ambigua. Mientras Bazin habla claramente de una identidad ontológica entre la cosa $(x)$ y su reproducción $(y)$, Carroll expone que $y$ es idéntico a $x$ en términos causales (1988, p. 133). Una explicación mecanicista que deja de lado la transferencia para centrarse nuevamente en la indexicalidad y la semejanza. 
una apariencia concreta dada, sino que además esa apariencia se vuelve fija; pierde su naturaleza cambiante. El peculiar modo de obrar de la fotografía y del cine nos presenta, pues, con una apariencia atemporal que se suma a la creación, que remite a un objeto real y que, sin embargo, es distinta de este. Retomando nuestro ejemplo, aunque Humphrey Bogart falleció en 1957, todos hemos visto su rostro. Bazin le dedicó un artículo a modo de epitafio en el que cerraba con una imagen del actor en Cayo Largo (Key Largo, John Huston, 1948), cuya nota a pie de foto versaba: “¿Muerto o vivo? El final de Cayo Largo nos lanza esta pregunta. El cine, memoria de los actores, nos conservará a Bogart vivo" (1957, p. 8). Podemos afirmar que, en cierto sentido, Bazin tenía razón: todavía hoy, seis décadas después de su muerte, Casablanca y El sueño eterno consiguen ponernos en la presencia del actor.

No es necesario que pasen años para experimentar esta sensación ante una imagen fotográfica. Basta con presionar el botón de una cámara actual para constatar en la pantalla del dispositivo cómo hemos capturado un momento fugaz para convertirlo en eterno. Según Bazin, la fotografía y el cine son esencialmente realistas porque la cámara conserva o inmortaliza lo registrado. En cierto sentido, la realidad visual del objeto se transfiere temporal y espacialmente de la realidad física al negativo de la cámara. Este efecto cobra una especial relevancia en el marco de la filosofía personalista, con la que Bazin guardaba un vínculo estrecho y gran afinidad. Desde esta perspectiva, la apariencia es más que un añadido, es un punto de acceso a la esencia de las cosas. La fotografía y el cine nos devuelven la imagen misma de la realidad. Y esto permite componer una representación que nos hable del mundo mediante su propia imagen, como ocurre en la realidad cotidiana.

Conviene apuntar que, si bien Bazin destaca este aspecto de la imagen fotográfica, no lo hace en detrimento de su complejidad, ni olvida las similitudes de esta respecto de otros tipos de imágenes que, según Dubois, se definen, o bien por su función mimética (semejanza entre la imagen y su modelo), la semiótica (mensajes implícitos, sean o no unívocos, que lleva aparejados dicha imagen) o la función pragmática (propia de la imagen fotográfica, pues cumple con los requisitos de la indexicalidad peirceana ${ }^{7}$ ).

7 A saber, el principio cuádruple de conexión física, singularidad, designación y atestiguamiento (Dubois, 1986, p. 50). 
Sin embargo, la fotografía no se resuelve, para Bazin, en ninguna de estas funciones, ni siquiera en la pragmática. Para Bazin, la imagen fotográfica es más que un parecido, un mensaje o un indicio de una realidad previa. La función de la fotografía para Bazin es, podría decirse, existencial, pues la transferencia da lugar a una cierta identidad ontológica entre el modelo y su imagen fotográfica.

\section{Características de la transferencia fotográfica}

Para lograr una comprensión de la transferencia que haga justicia al pensamiento de Bazin, es necesario dejar de lado las categorías semióticas y considerar la representación cinematográfica desde una perspectiva fenomenológica de tintes personalistas. Para la semiótica, la fotografía es un signo que actúa en el sentido de sustitución. Respecto de la ontología de Bazin, la fotografía no sustituye, sino que restituye la realidad. Este rasgo es heredado por el cine y, de acuerdo con Bazin, determina su aspecto más original respecto de otras artes. La fotografía es un tipo peculiar de huella. Las huellas son evidencia de la realidad, pero apuntan siempre hacia otra cosa. En cambio, siguiendo los planteamientos bazinianos, la huella fotográfica tiene la peculiaridad de que restituye por completo lo que la produce: la imagen del mundo. Una imagen fotográfica no apunta a otra cosa que al pasado de esa realidad que presenciamos. Una huella fotográfica no actúa como una pisada en la arena, que remite a algo distinto de sí misma: a un pie. Desde la perspectiva de Bazin, la imagen fotográfica apunta hacia sí misma: "La cámara ha operado esta misteriosa y paradójica acción fotográfica, al término de la cual lo que se nos da no es otra cosa que el conocer la realidad [tarducción mía]” (1947, p. 678). En este sentido, la fotografía es una apariencia que remite a sí misma en una temporalidad distante. ${ }^{8}$

A partir de este razonamiento, Bazin comprende que, como la imagen fotográfica restituye la realidad sin sustituirla, esta se une a la creación como fenómeno natural y nos afecta como tal (1945, p. 408). ${ }^{9}$ Es decir, la

8 Para profundizar en este aspecto que distingue la transferencia de la indexicaliad, $c f r$. Lebedev (2016).

9 En la compilación de textos para Qu'est-ce que le cinéma?, el término natural aparece entrecomillado (1958, p. 15), en lugar de en cursivas, como hace Bazin en su texto original. El entrecomillado pudo haber dado un sentido distinto al 
fotografía es un nuevo soporte, una nueva materia. Pero, en tanto se une, no reemplaza, como ocurre en el intento fallido del mapa borgiano 1:1 del conocido microrrelato (1992, p. 443). ${ }^{10}$ Pese a que en la imagen fotográfica la realidad sufre un proceso de transformación (de tres a dos dimensiones, de color a blanco y negro, etc.), Bazin destaca la particular manera en que la fotografía nos permite acceder al mundo: "Una fotografía en blanco y negro no es una imagen de la realidad descompuesta y recompuesta 'sin el color', sino una verdadera huella de la realidad, una especie de molde luminoso en el que el color no aparece. Hay identidad ontológica entre el objeto y su fotografía” (1966, p. 582)

Para lograr una comprensión cabal de esta premisa baziniana, es necesario señalar que creer en una identidad ontológica absoluta, sin matices ni explicaciones, entre el modelo y su fotografía sería igualmente falso. Los matices y las explicaciones necesarios, y que Bazin obvió en "Ontologie”, llegarán de la mano de Cavell en la década de los setenta. El filósofo norteamericano describe una identidad entre la imagen real del objeto y la imagen fotográfica de este. La fotografía no es una representación en el mismo sentido que lo es la pintura, porque la fotografía re-presenta la imagen propia del objeto, lo cual implica dos cosas: que trae al presente algo que se encontraba en el pasado y que la imagen del objeto pasado y la imagen del objeto re-presentado son iguales. La similitud con la teoría baziniana es evidente y nos ofrece un desarrollo teórico pertinente para indagar el concepto baziniano de transferencia.

buscado por el autor, ya que al aparecer entre comillas el término naturalpodría cobrar un sentido metafórico. Aquí ofrecemos el texto original y la traducción española: "La fotografía obra sobre nosotros como fenómeno 'natural', como una flor o un copo de nieve en el que la belleza es inseparable del origen vegetal o telúrico” (1966, p. 18). "Elle agit sur nous en temps que phénomène naturel, comme une fleur ou un cristal de neige dont la beauté est inséparable de leur origine végétale ou tellurique" (1945, p. 408).

10 En este punto, la lectura baziniana de la fotografía se encuentra en el extremo contrario a la de Jean Baudrillard, quien lleva la metáfora de Borges a un siguiente nivel: "El territorio ya no precede al mapa ni le sobrevive. En adelante, será el mapa el que preceda al territorio" (1984, pp. 9-10). Para Bazin, una fotografía, a diferencia de la cartografía, no busca sustituir, sino hacer presente ese territorio que existe (en el pasado). Desde esta perspectiva, la imagen fotográfica tiene un cometido opuesto al de las imágenes de Baudrillard. De acuerdo con Bazin, las fotografías inmortalizan la realidad, mientras que para Baudrillard las imágenes la exterminan, simulando una realidad falsa (1984, p. 17). 


\section{Presentificación del pasado}

Cavell aporta un matiz al modo de comprender la presencia del objeto en la imagen fotográfica cuando afirma que vemos cosas ante las que nosotros no estamos presentes, aunque estas sí se encuentran presentes ante nosotros (1979, pp. 18-23). Esta presencia cavelliana trabaja con la noción de objetividad fotográfica descrita en "Ontologie" por Bazin, cuya principal consecuencia es propiciar la credibilidad del espectador en lo representado:

Esta génesis automática ha trastocado radicalmente la psicología de la imagen. La objetividad fotográfica le da una potencia de credibilidad ausente de toda obra pictórica. Sean cuales fueren las objeciones de nuestro espíritu crítico nos vemos obligados a creer en la existencia del objeto representado, re-presentado efectivamente, es decir, hecho presente en el tiempo y en el espacio . (1958, pp. 15-16)

Rosen (2001) ha realizado un estudio sobre este aspecto de la objetividad fotográfica, en el que explica que la fotografía es, a la par, garantía de la existencia pasada de los objetos y presencia de ese objeto del pasado en la subjetividad del espectador. Según Rosen, la fotografía garantiza que ese objeto existió alguna vez, pero, "dado que este cuándo distinto no puede ser inmediatamente presente, debe ser 'rellenado', 'inferido', 'provisto' por el sujeto” (p. 21). La originalidad de las reflexiones de Cavell, al igual que las de Bazin, es que ambos dan un paso más allá al comprender la fotografía como una verdadera re-presentación del objeto, en el sentido de que vuelve a hacerlo presente (2005, pp. 117-118). En palabras de Cavell:

La fotografía mantiene la "presenteidad" del mundo al aceptar nuestra ausencia de él. La realidad de la fotografía se hace presente para mí aun cuando yo no le soy presente a ella; y conozco un mundo -y veo un mundo - en el que no estoy, sin embargo, presente (sin fallo alguno de mi subjetividad): un mundo pasado. (1979, p. 18)

La similitud de los términos utilizados entre estos autores denota la identificación hecha por ambos del proceso de transferencia, que supera la semejanza para instalarse en el plano de la existencia. Al respecto, Cavell nota que, mientras "una representación hace hincapié en la identidad de su sujeto, de forma que puede ser llamada parecido, una fotografía lo hace en la existencia de su sujeto, grabándolo, y de ahí que pueda llamarse transcrip- 
ción. También se puede pensar en ella como una transfiguración" (2005, p. 118). El término transfiguración al que alude Cavell tiene su origen en la teología sacramental cristiana, según la cual las especies consagradas en la eucaristía adquieren una nueva sustancialidad (el Cuerpo de Cristo) sin perder sus características perceptibles (pan y vino). En el texto de Cavell, este término sí es metafórico, pero de algún modo presenta una analogía: en la fotografía, la sustancialidad de la imagen se transfiere del objeto real al medio fotográfico. La imagen queda "momificada" en el nuevo medio, pero es la misma imagen del objeto.

Esta afirmación no deja de sonar paradójica. Sin embargo, describe un fenómeno real del que otros autores han tratado de dar cuenta en diversas ocasiones. Como ya se ha mencionado, Walton (2008) destaca como particularidad de la fotografía la manera en que, sin ser el objeto real, el sujeto la contempla como si estuviera presente. De un modo distinto, Rosen (2001) hace hincapié en la percepción del espectador y el investimiento subjetivo de credibilidad a este tipo de imágenes (pp. 20-21). Todos ellos son esfuerzos por indagar este proceso misterioso, pero solo Bazin y Cavell hablan de una presencia y no de una percepción. Ambos resaltan la objetividad de la imagen fotográfica en lugar de la subjetividad del espectador, porque, desde su punto de vista, la imagen fotográfica no duplica, sino que preserva un objeto visible existente, una imagen del mundo. Por ello, la credibilidad para Bazin (1958, p. 15) y Cavell (2005, pp. 20, 72) no es un añadido por parte del espectador, sino una consecuencia natural del automatismo de su génesis.

Una vez expuesto cómo se desarrolla la primera implicación de la transferencia, es decir, aquella que afirma que se nos presenta una realidad del pasado en el presente, se aborda ahora la segunda, que consiste en comprender en qué sentido son ontológicamente idénticos la imagen fotográfica y la realidad que re-presenta. Mientras la cualidad de presencia de la imagen fotográfica está vinculada con la preservación objetiva de una apariencia (credibilidad), la cualidad de identidad ontológica tiene que ver más con el proceso sustractivo realizado por la cámara, que tiene implicaciones materiales (en la imagen de registro) y subjetivas (en el espectador). 


\section{La identidad ontológica}

Para llegar a la comprensión del cine como re-presentador de realidades, Cavell parte, al igual que Bazin, de la génesis de la imagen: "La base del medio de las películas es fotográfica, y la fotografía es de la realidad o la naturaleza” (1979, p. 16). La relevancia de la causalidad en la génesis de la fotografía radica para Cavell en que, al observar una fotografía o un filme, sabemos que lo mostrado sucedió alguna vez frente a la cámara y que posee un correlato espacial. Por esto mismo, la imagen registrada no solo preserva un fragmento de la realidad de su corrupción temporal, sino que también apunta a ese correlato pasado, vinculando su existencia a algo que ya no vemos y que, sin embargo, no pierde su realidad, a pesar de haber quedado en el pasado. La cámara selecciona un fragmento y lo sustrae del resto del mundo físico, inmortalizándolo tal y como era, mientras que su correlato espaciotemporal se ha perdido para siempre. Por eso durante la proyección lo que vemos no posee un correlato presente, sino pasado: "que el mundo proyectado no existe (ahora) es su única diferencia con la realidad” (p. 24).

El interés en hablar del correlato temporal que ha quedado en el pasado viene porque esa es la única diferencia entre la percepción de ese objeto original (por ejemplo, durante el rodaje de una película) y la percepción de su reproducción cinematográfica (en la sala de proyección). Y es que esta transferencia de realidad nos permite hablar de que el cine nos da la realidad misma. Como señala Cavell, "una fotografía no nos presenta con una 'semejanza' de las cosas; nos presenta, queremos decir, con las cosas mismas” (1979, p. 17). Una frase que remite a la conocida afirmación baziniana, "[La fotografía] nos da el objeto mismo pero liberado de las contingencias temporales" (1958, p. 16), a la vez que recupera el lema clásico de la fenomenología como experiencia de la realidad: Sachen selbst zurückgehen! ${ }^{11}$ Lo que ofrece la imagen fotográfica es precisamente una experiencia de "la cosa misma".

Bazin habla del "objeto mismo" (1958, p. 16) y, aunque lo parezca, esta idea no es un disparate, sino una paradoja. En sus Lecciones fenomenológicas sobre la conciencia interna del tiempo, Husserl explica que la tempo-

11 “AA las cosas mismas!” (Husserl, 2006, párr. 4). 
ralidad es una sucesión de "ahoras" que, en su transcurrir natural, quedan fijados en el pasado. Mediante el método fenomenológico de conocimiento, ese "suceso [pasado] es traído al presente y discurre ante la conciencia tal como antes se dio perceptivamente (caso del recuerdo)" (2002, p. 10). Pues bien, el cine como momificador del cambio no solo preserva el pasado con una objetividad imposible de conseguir en el simple recuerdo, sino que además reinserta ese objeto fijado en nuevos "ahoras". Esta comprensión del tiempo y el cine es lo que subyace, en gran parte, a las teorías de Cavell y Bazin cuando hablan de transferencia. ¿Qué significa que el objeto sea "re-presentado efectivamente, es decir, hecho presente en el tiempo y en el espacio" (1958, p. 16)? Que la fotografía posibilita que una realidad pasada adquiera una nueva materialidad, de modo que se contempla en el medio fotográfico como si estuviera ante la memoria. Sería atrevido afirmar que Bazin leyera directamente a Husserl, aunque su influencia puede haberle llegado vía los filósofos e intelectuales que Bazin leía y frecuentaba, como Jean-Paul Sartre, Maurice Merleau-Ponty o Emmanuel Mounier, pero sí puede comprenderse la imagen cinematográfica como re-presentación en el sentido fenomenológico del término. ${ }^{12}$ La aproximación fenomenológica y la baziniana son formas de pensamiento emparentadas: la preservación baziniana de la fotografía supone la posibilidad de traer fenomenológicamente ante la conciencia un objeto específico gracias a una materialidad determinada.

Retomando un ejemplo de Cavell, ${ }^{13}$ es evidente que una fotografía de Pedro no es Pedro mismo, pero tampoco nos atreveríamos a señalar la fotografía y decir “este no es Pedro". Negar que el de la fotografía es Pedro sería también paradójico e incluso falso, aunque el sentido de esa negación tenga lógica: no vemos a un ser humano, sino una fotografía. Como lo expone Rothman, "tanto para Cavell como para Bazin el misterio de las imágenes fotográficas reside en su capacidad de permitir que personas y cosas del mundo se presenten, se revelen, a sí mismas" (2007, p. 56).

12 La re-presentación es entendida como Vergegenwärtigung en el sentido de evocación existencialmente ligada a la realidad de la cosa (cfr. Husserl, 2002, p. 19).

13 Sartre y Bazin emplean este mismo ejemplo. Cavell emplea el nombre Garbo (1979, p. 17), mientras que Bazin y Sartre habían hablado de Pierre (Sartre, 1940, p. 41). 
Debido a esta presencia de lo ausente, la ontología de la imagen fotográfica adquiere un nuevo nivel de complejidad. Cavell señala la complejidad de comprender la conexión existente entre la realidad y su fotografía porque su relación no es de semejanza: la fotografía no es una sombra, ni una réplica, ni una reliquia, ni una aparición... Aunque guarda parecido con todas estas. Para facilitar su comprensión, Cavell compara la visión (sight) y el sonido (sound). Según el método cavelliano, cuando alguien escucha una grabación sonora, no duda en decir "eso que se escucha es un violín"; en cambio, nadie dice, "no es un violín sino una grabación de un violín". Es el mismo ejemplo de la fotografía de Pedro pero aplicado ahora al sonido del instrumento musical. Ambas son reproducciones y nos recuerdan al original.

Aunque esta formulación podría funcionar, Cavell nota que es necesario tener en mente dos diferencias entre la imagen y el sonido. La primera es que mientras es habitual escuchar sonidos de cosas que no están presentes, con la imagen no pasa lo mismo porque no creemos posible ver cosas que no lo están. Y, sin embargo, "esto parece ser, ontológicamente, lo que está sucediendo cuando vemos una fotografía: vemos cosas que no están presentes" (1979, p. 18). Cavell no niega que veamos algo presente (la fotografía misma), pero también vemos algo que no está presente (a Pedro). Cabe recordar que el texto que abre el primer volumen de Qu'est-ce que le cinéma? lleva por título "Ontologie de l'image photographique". Una primera pista de que Bazin no se centra en el soporte sino en la imagen. En este sentido, Cavell y Bazin parecen apuntar hacia lo mismo (l'image, sight), con independencia de si su soporte es el objeto que lo produce o la huella que la luz haya dejado en un filme.

La segunda diferencia entre sonido e imagen es que al escuchar la melodía de un violín no escuchamos el violín sino su sonido. Y ese es el mismo sonido que escuchamos en la grabación al reproducirla. Pero con las fotografías es diferente:

El problema es que aun si una fotografía fuera una copia de un objeto, por así decir, no tendría la misma relación con su objeto que una grabación con el sonido que copia. Decimos que el disco reproduce su sonido, pero no podemos decir que una fotografía reproduce una visión. (1979, p. 19) 
Cuando escuchamos algo, percibimos el sonido que produce, pero cuando vemos algo, lo que percibimos no es una visión producida sino el objeto: "Lo que ves cuando ves algo es un objeto, en todo caso, no es la vista de un objeto" (1979, p. 20). Cavell explica la diferencia entre "visión producida" y "objeto visto" señalando que, a diferencia de lo que ocurre con el sonido, la visión no es algo que el objeto produzca, sino algo constitutivo del objeto. Un violín, aunque no suene, sigue siendo un violín. Y el sonido del violín remite a este objeto. En cambio, al ver un violín o la fotografía de un violín, lo que se ve es el objeto mismo, "los objetos no hacen vistas, o tienen vistas" (1979, p. 20). En esta frase, Cavell no separa el acto manifestativo del objeto del objeto en sí; es decir, lo que nosotros vemos, según Cavell, es lo mismo que el objeto es. Esto último apunta hacia la centralidad que desempeña el sujeto en la teoría de Cavell y, como se verá a continuación, también en la de Bazin.

\section{Reconocimiento}

Una vez aclarados los argumentos centrales relativos a la materialidad del medio, es momento de abordar el modo en que se desarrolla el "reconocimiento" bazin-cavelliano de la transferencia por parte del sujeto. Tanto Bazin como Cavell sostienen que, durante la proyección cinematográfica, en la pantalla se nos presentan los objetos mismos, sustraídos del cauce temporal y que mediante estos se nos ofrece una ventana para mirar el mundo. Ambos se mueven a caballo entre la descripción del fenómeno en sí y la recepción de dicho fenómeno por parte de los espectadores. La presencia del objeto, posibilitada mediante la transferencia, alude al proceso objetivo mediante el cual la cámara registra de manera automática una realidad pasada, mientras que la identidad ontológica requiere necesariamente un sujeto que la reconozca como tal, ya que es una identidad en la visión o apariencia. Pero hablar de la acción cognoscitiva del espectador no significa que la transferencia sea, al fin y al cabo, un asunto propio de la creencia o del como $s i$, tal y como señalaban Rosen y Walton. La diferencia entre la centralidad del sujeto aquí y en aquellas lecturas estriba en que para Bazin y Cavell el sujeto no rellena ningún gap (Rosen, 2001, p. 21) ni suspende su incredulidad (Walton, 2008, p. 83), sino que tan solo reconoce la realidad de las imágenes fotográficas, que nos permite acceder a ella. 
Nuestro primer acceso al conocimiento del mundo es sensible, a través de los fenómenos. Y, por tanto, es a partir de la sensibilidad como la persona aprehende lo que las cosas son. Por eso Husserl no habla de tiempo, sino de "aparición" de tiempo, así como no puede hablar de un pasado objetivo, sino de un "ahora" que se "representifica" mediante la memoria (2002, pp. 27-28). En este sentido, el cine y la fotografía cumplen con la función de presentarnos los contenidos primarios (sensibles) necesarios para nuestra aprehensión del mundo. De esta manera, en el cine presenciamos los fenómenos del mundo: nos encontramos ante un mundo visto ( $a$ world viewed), aunque no vivido.

Gracias a la transferencia de realidad, es posible reconocer un mundo sensible que existe con independencia de nuestra subjetividad (algo que no ocurre en otras imágenes) y que se nos presenta, como afirma Cavell, como "una sucesión de proyecciones automáticas del mundo" (2005, p. 72). También puede ser interpretado, como diría Bazin, como una alucinación verdadera. En la imagen cinematográfica, el sujeto reconoce la realidad. Quizá de un modo más claro o consciente en aquellas obras con intención documental, como Farrebique ou Les quatre saisons (Rouquier, 1946), en la que, según apunta Bazin, la realidad posee un espacio propio, sin subordinarse a la dimensión artística o compositiva, a pesar de que estas conviven armónicamente con aquel: "Tras cincuenta años de realismo cinematográfico, bajo un plano de realidades sin duda muy superior, no hizo falta más que un poco de genialidad para restituir al público este gozo simple y elemental que el cine novelesco y dramático ya no ofrecen: el gozo del reconocimiento" (1947, p. 679).

La realidad física se conoce, pero en la fotografía y en el cine esa realidad se re-conoce. Es decir, el sujeto reconoce la realidad de esas imágenes. No solo la realidad que las originó (causalidad), ni la realidad que retratan (objetividad), sino la realidad ante la que se encuentra presente.

Por este motivo, el reconocimiento (reconnaissance, acknowledgement ${ }^{14}$ ) es algo específico del cine y la fotografía. Para reconocer algo, esto debe te-

14 Tanto Bazin como Cavell, al explicar el modo en que la ontología de la imagen fotográfica afecta la percepción del sujeto, acuden al término reconocimiento (reconnaissance o acknowledgement). Pero aquí Cavell, a diferencia de otros 
ner una existencia. Por eso no basta con contar con cualquier imagen por muy fotorrealista que esta sea, ya que lo que está en juego no es un problema de semejanza o perfección visual (likeness), sino de presentidad (presentness) del mundo, que conocemos mediante las imágenes fotográficas. No debemos olvidar, sin embargo, que el reconocimiento - como acción subjetiva que es - es posible gracias a la cualidad icónico-indexical de la imagen. Si no podemos distinguir lo representado, tampoco podemos reconocerlo, como ocurre al caminar a oscuras o en la fotografía abstracta de Man Ray. En ambos casos, no se trata de que el objeto no esté presente. La mesita de noche estará ahí para interponerse en mi camino hacia el salón, así como la realidad se posa ante el objetivo del conocido fotógrafo dadaísta. Objetos y personas están ahí (transferencia), aunque yo no los reconozca (iconicidad, indexicalidad). El desarrollo técnico del cine busca, por supuesto, alcanzar una mayor precisión en el detalle, pero estas mejoras no contrarían su ontología. La presentidad de la imagen cinematográfica, explica Cavell, no es exactamente "una convicción de la presencia del mundo para nosotros, sino de nuestra presencia para él” (2005, p. 21). Esto resulta fundamental, según Cavell, porque opera como un intento de superar el escepticismo en el que se ve sumergida la modernidad: el cine es un modo de creer en la realidad, de evidenciar su existencia como algo independiente del sujeto que la percibe.

Como explica Cavell parafraseando a Hegel, cuando una persona comienza a ser consciente, la auto-conciencia es inicialmente una separación: decir "yo" es distinguirse del mundo. Y para Cavell esta separación comporta una sensación de aislamiento (2005, p. 22). De ahí que el arte busque demostrar la presencia de la persona dentro del mundo. ${ }^{15}$ La conciencia de

puntos de su teoría, no estaba haciendo referencia consciente al término utilizado por Bazin, ya que Cavell solo tuvo acceso a los textos compilados en Qu'est-ce que le cinéma? y “Farrebique ou le paradoxe du réalisme”, en los que Bazin se refiere al fenómeno con ese término. Sin embargo, Bazin sí había apuntado a la operación llevada a cabo por el espectador por medio de la cual reconoce y re-conoce la realidad en el primer volumen de su compendio de artículos.

15 Este mismo fenómeno ha sido abordado por parte de Walker Percy en The Moviegoer, una novela moderna de corte faulkneriano e inspiración existencialista, en la que Percy explora la alienación de un joven que solo encuentra sentido en las películas y en los libros. El siguiente fragmento complementa el diagnóstico realizado por Cavell a propósito de ser un yo en el mundo mediante las películas. Un fenómeno, por lo demás, profundamente moderno: "Hay una escena que muestra precisamente el vecindario donde está el cine. Kate me lanza una mirada -tenemos el pacto de no hablar durante la proyección en la sala. 
esta pertenencia es algo que el cine consigue definitivamente, porque, mientras el arte subraya el yo del artista que crea, el cine destaca la presencia del ser en el mundo. Lo que se establece gracias a esta presentidad es una conexión con la realidad, una reparación de esa fractura producida por la autoconciencia entre la persona y lo otro.

Por eso Cavell coincide también con Bazin en que el automatismo de la fotografía desbanca a la pintura como satisfactora de la necesidad humana por la semejanza (complejo de la momia). Con la fotografía, por fin se remueve la subjetividad del pintor, lo cual permite que las imágenes dejen de ser una autoafirmación del artista o una expresión de su propio ser y pasen a constituir un reencuentro entre el sujeto que mira y el mundo en que habita.

En el marco de la teoría baziniana, en definitiva, no se dota a una imagen de realismo: este se reconoce. Para Bazin y Cavell, la tendencia realista de la imagen fotográfica no requiere un investimento subjetivo, pues a la imagen fotográfica el realismo ya le viene implícito, como ocurre con las imágenes que vemos en la realidad. ¿Qué hay más realista que un rostro? En el epitafio a Bogart realizado por Bazin, encontramos materializada esta idea: en el fotograma de Cayo Largo previamente descrito accedemos a la presencia de un rostro que, como sentenciaba Robert Lachenay, era el de un cadáver incluso años antes de su muerte (1957,pp. 2-8). Este es el ineludible desenlace de la vida y el patente sino de la imagen fotográfica.

\section{Conclusiones}

Mediante los planteamientos propuestos por André Bazin y más tarde desarrollados por Stanley Cavell, podemos afirmar que la imagen fotográfica y cinematográfica produce un efecto único en el espectador, que ocupa un sitio intermedio entre la percepción de la realidad visible en el mundo físi-

\footnotetext{
Más tarde, en la calle, ella mira en el barrio a su alrededor. 'Sí, ya está certificado'. Se refiere al fenómeno del moviegoing que consiste en lo que he llamado certificación. Actualmente, cuando una persona vive en algún sitio, en un vecindario, el sitio todavía no ha sido certificado. Lo más probable es que el pobre viva allí una existencia triste y vacía que impregne el vecinadrio entero. Pero, si esta persona ve una película en la que s emuestra ese vecindario en el que vive, de pronto todo se torna distinto en su vida y, al menos por un tiempo, esa persona será alguien que vive en un sitio y no en ningún sitio" (1998, p. 63).
} 
co y la que acontece en las artes plásticas. Se trata de la acción de reconocimiento, que tanto Cavell como Bazin atribuyen al proceso de transferencia.

Bazin afirma que en las imágenes fotográficas y cinematográficas los espectadores acceden a las cosas mismas. Es decir, el teórico francés refiere una identidad ontológica entre la imagen de registro y su modelo. Esta afirmación, que podría sonar paradójica, se entiende mejor cuando se define el objeto de estudio de este autor, es decir, al considerar que en "Ontologie” Bazin se esmera por describir la imagen fotográfica y no la fotografía (soporte físico en papel o celuloide + imagen de registro). Por ello, Stanley Cavell, al partir de las premisas bazinianas, aporta un matiz importante al clarificar pormenorizadamente que la identidad ontológica existe en lo relativo a la visión que nos presenta una imagen fotográfica o cinematográfica y la visión del objeto registrado.

El proceso por medio del cual se consigue esta identidad tiene sus propias peculiaridades en las teorías de Bazin y Cavell, pues ambos obvian el hecho de que la imagen de registro funciona como un índice de la realidad y comporta una semejanza evidente hacia ella. Para ambos, el modo en que la imagen de registro captura la visión de un objeto debe ser comprendida más desde el punto de vista de la restitución que de la sustitución, porque la imagen resultante nos presenta con una evidencia de una realidad pasada que al haber sido registrada es sustraída del cauce temporal. Se inmortaliza mediante el proceso automático de la cámara. De manera que, como diría Cavell, el cine nos presenta con una sucesión de proyecciones automáticas del mundo, es decir, con la imagen del mundo que, pese a haber sido sustraída del cauce temporal, se reinserta en este para representarnos el transcurrir temporal de dicha imagen. Por eso, Bazin hablaba de la momificación del cambio.

Por último, cabe decir que tanto Bazin como Cavell se esmeran por caracterizar la imagen de registro en sí, pero que, para dar cuenta de ella, ambos ven necesario determinar qué ocurre en la percepción de estas imágenes. El espectador reconoce (reconnaît, acknowledges) la realidad representada. Este enfoque se distingue, pues, de otras interpretaciones del 
efecto de la imagen fotográfica y cinematográfica en el espectador, ya que desde la perspectiva de nuestros dos autores el sujeto no inviste de realismo a la imagen, sino que la reconoce, de un modo análogo a como ocurre en la realidad física cotidiana.

\section{Referencias}

Andrew, D. (1993). Las principales teorías cinematográficas. Madrid, España: Rialp.

Andrew, D. (2010). What cinema is! Bazin's quest and its charge. Hoboken, EE. UU.: Wiley-Blackwell.

Andrew, D. (2013). André Bazin. Nueva York, EE. UU.: Oxford University Press.

Andrew, D. \& Joubert-Laurencin, H. (Eds.) (2011). Opening Bazin: Postwar film theory and its afterlife. Nueva York, EE. UU.: Oxford University Press.

Baudrillard, J. (1984). Cultura y simulacro. Barcelona, España: Kairós.

Bazin, A. (1945). Ontologie de l'image photographique. Confluences, 1, 405-411. Recuperado de https://bazin.yale.edu/ontologie-de-limage-photographique

Bazin, A. (1947). Farrebique ou le paradoxe du réalisme. Esprit, 132, 676680. Recuperado de https://esprit.presse.fr/article/andre-bazin/ farrebique-ou-le-paradoxe-du-realisme- 21826

Bazin, A. (1953). Le langage de notre temps. En Autor, Regards neufs sur le cinéma (pp. 14-16). París, Francia: Le Seuil.

Bazin, A. (1957). Mort d'Humphrey Bogart. Cahiers du Cinéma, (68), 2-8.

Bazin, A. (1958). Qu’est-ce que le cinéma? París, Francia: Éditions du Cerf. 
Bazin, A. (1966). ¿Qué es el cine? Madrid, España: Rialp.

Bazin, A. (2014). Andre Bazin's new media. Oakland, EE. UU.: University of California Press.

Bertoncini, M. (2009). Teorie del realismo di André Bazin. Milán, Italia: LEDEdizioni Universitarie de Lettere Economia Diritto.

Borges, J. L. (1992). Obras completas. Barcelona, España: Círculo de Lectores.

Brubaker, D. (1993). Andre Bazin on automatically made images. Journal of Aesthetics and Art Criticism, 51(1), 59-67. DOI: 10.2307/431971

Carroll, N. (1988). Philosophical problems of classical film theory. Princeton, EE. UU.: Princeton University Press.

Cavell, S. (1979). The world viewed: Reflections on the ontology of film. Cambridge, EE. UU.: Harvard University Press.

Cavell, S. (2005). Cavell on film. Albany, EE. UU.: State University of New York Press.

Dubois, P. (1986). El acto fotográfico: de la representación a la recepción. Barcelona, España: Paidós.

During, L. \& Trahair, L. (2012). Belief in cinema. Angelaki, 17(4), 1-8. 10.1080/0969725X.2012.747326

Esqueda-Verano, L. (2018). La ontología de la imagen híbrida: actualización de las premisas ontológicas en la teoría de André Bazin. Fotocinema: Revista cinetífica de cine y fotografía, 16, 243-264. Recuperado de: http://www.revistas.uma.es/index.php/fotocinema/article/ view/4095/3812 
Friday, J. (2005). André Bazin's ontology of photographic and film imagery. The Journal of Aesthetics and Art Criticism, 63(4), 339-350. Recuperado de https://www.jstor.org/stable/3700510

Husserl, E. (2002). Lecciones de fenomenología de la conciencia interna del tiempo. Madrid, España: Trotta.

Husserl, E. (2006). Meditaciones cartesianas. Madrid, España: Tecnos.

Lebedev, O. (2016). La robe sans couture de la réalité: André Bazin et l'apologie du réalisme cinématographique. Bulletin d'analyse phénoménologique, 12(4), 189-209. https://popups.uliege.be:443/17822041/index.php?id=870

Morgan, D. (2006). Rethinking Bazin: Ontology and realist aesthetics. Critical Inquiry, 32(3), 443-481. 10.1086/505375

Morgan, D. (2015). Stanley Cavell: The contingencies of film and its theory. En M. Pomerance \& R. B. Palmer (Eds.), Thinking in the dark: Cinema, theory, practice (pp. 162-173). New Brunswick, EE. UU.: Rutgers University Press.

Percy, W. (1998). The Moviegoer. Nueva York: Vintage Books.

Rosen, P. (2001). Change mummified: Cinema, historicity, theory. Minneapolis, EE. UU.: University of Minnesota Press.

Rothman, W. (2007). Bazin as a Cavellian realist. Film International, 5(6), 54-61. DOI : 10.1386/fiin.5.6.54

Rouquier, G. (1946). Farrebique ou Les quatre saisons [Documental]. Les Films Etienne Lallier.

Sartre, J.-P. (1940). L'imaginaire : psychologie phénoménologique de l'imagination. París, Francia: Gallimard. 
Smith, D. (2013). Introduction: Revisiting André Bazin. Paragraph, 36(1), 1-9. 10.3366/para.2013.0074

Totaro, D. \& Younger, P. (2003). Focus on Bazin. Off Screen, 7. Recuperado de https://offscreen.com/issues/view/vol7_7

Ungaro, J. (2000). André Bazin: généalogies d'une théorie. París, Francia: L'Harmattan.

VV. AA. (2007). Feature Bazin. Film International, 5.

Walton, K. L. (2008). Marvelous images: On values and the arts. Nueva York, EE. UU.: Oxford University Press.

Wollen, P. (1972). Signs and meaning in the cinema. Blomington, EE. UU.: Indiana University Press. 